\title{
SOBRE PESQUISADORES FELIZES E INFELIZES...
}

$\mathrm{Na}$ condição de pesquisadoras, as pessoas são indagadas sobre vários aspectos. Ultimamente, uma das questões mais recorrentes é: "você tem produção?". A resposta, se afirmativa, já é dada em termos que aludem a dados quantitativos, não envolvendo, de modo geral, um pronunciamento sobre a qualidade do produto. Isso tem despertado preocupação quanto aos rumos da produção científica, o que se evidencia nas tentativas de encontrar alternativas de avaliação que não se pautem exclusivamente em termos quantitativos. Não obstante a importância dessa discussão, gostaria de deslocar o foco do produto para o processo de produção, lançando perguntas que tangenciam as condições psicológicas das atividades de construção do conhecimento científico (orientação de dissertações, teses, redação de artigos, coordenação de grupos de pesquisa e de programas de pós-graduação etc.). Estou interessada, mais precisamente, neste conjunto de questões: os pesquisadores gostam daquilo que fazem? Eles fazem aquilo que gostam? Sentem prazer na atividade que dá sentido à sua própria condição de pesquisador, qual seja, a produção de conhecimento científico? Em última instância, a pergunta central é: os pesquisadores são felizes?

Talvez seja possível encontrar uma resposta na sabedoria dos antigos. As considerações de Epicuro $(341,342$ ou 351 AEC - 270 AEC) sobre a felicidade podem lançar alguma luz sobre essa problemática. Para ele, felicidade, a principal meta a ser buscada por todos nós, é sinônimo de prazer. Passemos a palavra ao filósofo: "O prazer é o princípio e o fim da vida feliz" (cf. Laêrtios, 2008, p. 312). Uma pessoa feliz é aquela que sente prazer naquilo que faz. Além disso, na teoria epicurista, a felicidade se traduz na "saúde do corpo" e na "tranquilidade da alma", "pois isto"- diz Epicuro - "é a realização suprema de uma vida feliz" (cf. Laêrtios, 2008, p. 312). Com efeito, o prazer de viver advém de um corpo sadio e de um "espírito" não perturbado, não ansioso, não delirante, mas sereno.

Destoando da vulgata hedonista, que confunde a filosofia epicurista com a prescrição de opulência, orgias, banquetes e toda sorte de prazeres desmedidos, Epicuro defendia que para alcançar a felicidade é preciso usarmos de modo racional os prazeres. Trata-se, pois, de um "aritmética dos prazeres" e de uma "dietética dos desejos" (cf. Onfray, 2006/2008, p. 201). Nessa perspectiva, nem todos os prazeres devem ser buscados e nem todo sofrimento deve ser poupado. Precisamos, por exemplo, evitar os prazeres advindos das extravagâncias, como os excessos de comida e de bebida, pois ameaçam nossa integridade orgânica. Precisamos, igualmente, evitar prazeres provindos da bajulação, de honrarias e de outras formas de exaltação pessoal. Segundo Epicuro, esses tipos de prazer podem abalar a serenidade, deixando as pessoas inquietas, pois aquelas que não os têm fazem de tudo para tê-los, e aquelas que os têm fazem de tudo para não perdê-los. Enfim, são pessoas sempre perturbadas pela ambição e pelo temor das perdas.

Para Epicuro esses desejos não são necessários para uma pessoa ser feliz. Mesmo sendo desejos e gerando prazer imediato, eles podem, em momento ulterior, produzir sofrimento, deteriorando o corpo e comprometendo nossa paz. Inversamente, Epicuro admoesta que há sofrimentos que devem ser enfrentados, se eles acarretarem um prazer maior em longo prazo. Isso exige o exercício do autocontrole: evitar, por exemplo, o excesso de comida e de bebida em favor da saúde do corpo; evitar sucumbir a um ataque de fúria, contendo palavras ofensivas em prol da garantia de uma boa amizade. 
Voltando à questão central: os pesquisadores são pessoas felizes? Estudos mostraram relações entre problemas orgânicos e altos índices de produtividade, como o de Santana (2011), que verificou, em uma amostra de docentes de pós-graduação, uma correlação positiva entre número de publicações e de orientandos (em média, por ano) e doenças cardiovasculares. Somando-se a isso, o ritmo vertiginoso de produção, o acúmulo e a sobreposição de atividades acadêmicas e administrativas podem gerar problemas psicológicos, como crises de ansiedade, depressão, síndrome do pânico, síndrome de burnout e outras mazelas que abalam a tranquilidade do nosso "espírito". Ainda no rastro de Epicuro, há outras fontes de perturbação da "alma" no âmbito acadêmico: a bajulação e a busca por prêmios e condecorações. É claro que o reconhecimento social por um trabalho bem feito pode ser fonte de prazer. O problema é o fato de ele ser a única fonte de satisfação, de modo que todo o trabalho passe a ser regido pela busca de sucesso financeiro e aclamação profissional. Artifícios como elogios, dinheiro ou prêmios podem até ser úteis para que o neófito comece a desfrutar do prazer advindo da própria atividade de produzir conhecimento; ou mesmo para dar novo fôlego ao pesquisador veterano; no entanto, muitas vezes a academia organiza condições para que essas estratégias acabem se tornando um fim em si mesmas. Isso acontece quando, por exemplo, distribuem-se desigualmente favores (privilégios), que vão desde o pagamento de diárias em hotéis, refeições requintadas em lugares diferenciados até outras formas de distinção que criam uma atmosfera de glamour e admiração à pessoa beneficiada, nutrindo os anseios daqueles que almejam um dia ser como ela.

Quando é regido por consequências externas à própria atividade de pesquisar, o trabalho acadêmico pode se desvirtuar. O objetivo da prática de pesquisa deixa de ser a produção de conhecimento novo, criativo, com potencial de transformação social, para se voltar à satisfação de outros "desejos". A preocupação passa a ser a de enriquecer o currículo lattes, que, de efeito da atividade acadêmica, torna-se sua força motriz. No tocante às relações interpessoais, é possível que um colega de trabalho seja tratado apenas como uma pessoa capaz de alavancar ou comprometer a avaliação de um programa de pós-graduação: se a sua produção decair, começa a ser visto com maus olhos, sendo uma iminente ameaça à qualidade do programa; mas se a produção aumentar, ele é bem-vindo, podendo até angariar alguns privilégios. Caso o colega seja acometido por alguma doença, o que não é incomum nessas circunstâncias, a preocupação muitas vezes recai na possível interferência dessa enfermidade em seu desempenho profissional.

Se a dinâmica acadêmica for conduzida nesses moldes, o contato entre orientador e orientando pode ser reduzido a uma relação mercantil, na qual o bem comercializado é o conhecimento na forma de artigo. Neste caso, o orientando é avaliado pela sua capacidade de produzir artigos que possam ser publicados, de preferência, em uma revista bem-qualificada. Em outras palavras, o orientando é visto como um artigo em potencial. Nessas bases, a orientação deixa de ser um contexto de formação em que o orientador lê e discute o trabalho do orientando, auxiliando-o no processo de produção de conhecimento para que no futuro ele se torne um pesquisador. Em nome da defesa de uma suposta "autonomia" do aluno, as relações face a face na orientação tornam-se cada vez mais escassas e seu trabalho passa a merecer atenção somente quando adquirir os contornos de um artigo para eventual publicação.

Somando-se a isso, as aparentes relações de cooperação acadêmica podem constituir, ao invés de um grupo de pesquisa, um "bando de pesquisa" (Volpato, 2013, p. 333): um conjunto de pesquisadores que compartilham autorias de trabalhos de cuja proposição, execução e desfecho eles não participaram efetivamente. De novo, os laços são para aumentar a produção, e não necessariamente a qualidade do que é produzido. Nessa toada, fortalecem-se relações de interesse, em que as aproximações interinstitucionais não são pautadas, em última instância, por afinidades teóricas ou pela qualidade do trabalho com o qual se pretenda estabelecer um diálogo, mas pelo fato de esses acordos contabilizarem mais pontos na avaliação institucional.

As relações acadêmicas ficam, então, brutalizadas, sendo regidas por uma "moralidade de tecnologia" (Bauman, 1996/1998, p. 188), em que as ações são julgadas pela sua eficiência em 
cumprir tarefas e prazos, e não pelo seu caráter moral. Em outras palavras, ações boas tornamse ações eficientes, cuja virtude é aferida pela precisão com que as regras são obedecidas e pelos resultados obtidos com a execução das tarefas. A moralidade de tecnologia engendra uma insensibilidade ao outro, tornando-nos refratários a discussões éticas no contexto acadêmico. Essas, por vezes, passam ao largo da atividade científica, ou, quando muito, são tratadas como questões secundárias a ela. A negligência desses assuntos pode levar-nos a considerar "naturais" práticas antiéticas. Sobre esse ponto, Volpato (2011) alerta:

Se você acredita que a pressão por publicação leva à autoria fraudulenta, repense. Isso não tem sentido lógico. O que leva à autoria fraudulenta é a corrupção moral e ética do indivíduo, nada mais. Conheço pessoas que preferem ser 'improdutivas' a ser autores fraudulentos. Não é uma questão técnica, é moral (p. 337).

Tudo isso gera um ambiente hostil, no qual a competição é a tônica das relações: o outro é visto como ameaça ao nosso sucesso profissional, e a falta de confiança apresenta-se como uma condição necessária para estabelecer novos "relacionamentos". Ademais, as conversas tornamse cada vez mais restritas a torpedos e e-mail, com a justificativa da falta de tempo; mas às vezes tais mediações servem de pretexto para que ofensas sejam proferidas a colegas - algo presumivelmente mais difícil de acontecer em ambiente real e não virtual. Em suma, a partir da ótica epicurista, criamos um contexto propício para a deterioração do corpo e para a "perturbação da alma", enfim, para a infelicidade.

É preciso que a atividade de pesquisa seja fonte de prazer; no entanto, como exorta Epicuro, é preciso "calcular" os prazeres de modo a não gerarem sofrimento ulterior. Há pessoas que dedicaram a vida toda exclusivamente ao trabalho acadêmico, tornando-o sua única fonte de prazer. Em longo prazo, essa restrição das fontes de prazer pode acarretar profundo sofrimento. É o que se verifica, por exemplo, em casos nos quais a pessoa, na iminência da aposentadoria, sente-se desorientada, perdida, angustiada. Isso acontece porque ela não criou fontes de prazer alternativas ao trabalho, seja por ter deixado de criar laços com a família, tornando o ambiente familiar algo estranho e desconfortável em comparação com o acadêmico, seja por não ter cultivado amigos fora do ambiente profissional, seja ainda por não ter-se engajado em atividades de lazer ou por outras razões.

Precisamos mudar esse quadro. Precisamos de pesquisadores felizes, que façam o que gostem e gostem do que façam. Precisamos de pesquisadores cujo trabalho seja regido pelo prazer advindo da própria atividade de pesquisar: o prazer da descoberta, da solução de um problema, da ampliação do conhecimento, da formulação de uma nova pergunta, da mudança do comportamento do orientando que sinaliza a formação de uma pessoa competente e ética. Pessoas que sentem prazer no que fazem têm "calor e intimidade" (James, 1890/1955, p. 214) com o trabalho, com as pessoas nele envolvidas, e não frieza e distanciamento. Para essas pessoas o trabalho é fonte de satisfação, prazer, felicidade, e não só causa de angústia, pânico, ressentimento, dor, sofrimento e infelicidade.

Por sorte existem ainda indivíduos assim, felizes. Talvez eles sejam os modelos a ser seguidos. Inspirados neles, precisamos criar um contexto à semelhança do Jardim de Epicuro, onde homens e mulheres filosofavam sob o calor da amizade, sendo regidos pelo valor da justiça. Abandonando aspirações estoicas, precisamos nos voltar para condições de trabalho que levem em conta a saúde do nosso corpo e a tranquilidade de nossa "alma", enfim, condições que propiciem prazer. Precisamos reconsiderar nossa relação com o conhecimento e com as pessoas envolvidas nesse processo. Precisamos parar de gerar tanto sofrimento para nós mesmos e para os outros. Precisamos, antes de qualquer coisa, parar, algo que se torna cada vez mais difícil de fazer no ritmo vertiginoso de nossa sociedade líquido moderna.

Como fazer isso? Talvez começando a mudar nossas perguntas: em vez de indagar "quanto você produz?", perguntar "qual é a qualidade do que produz?", "qual é a qualidade do seu 
trabalho", "qual é a qualidade de suas relações de trabalho?"; em vez de começar com a pergunta da qual partimos ("você tem produção?"), talvez seja o caso de questionar: "você está feliz?".

\section{Profa. Dra. Carolina Laurenti \\ Editora de seção \\ E-mail: laurenticarol@gmail.com}

\section{REFERÊNCIAS}

Bauman, Z. (1998). Modernidade e holocausto (M. Penchel, trad.). Rio de Janeiro: Zahar. (Tradução autorizada da quarta edição inglesa publicada em 1996).

James. W. (1955). The consciousness of self. In R. M. Hutchins. (Ed.). The principles of psychology: Great books of the western world (pp. 188-259). Chicago: Enclycopaedia Britannica. (Original publicado em 1890).

Laêrtios, D. (2008). Livro X: Epícuros. In D. Laêrtios. Vidas e doutrinas dos filósofos ilustres (2a ed., M. da G. Kury, trad., p. 312). Brasília: Editora Universidade de Brasília.

Onfray. M. (2008). Contra-história da filosofia 1: as sabedorias antigas (M. Stahel, trad.). São Paulo: Martins Fontes. (Original publicado em 2006).

Santana, O. A. (2011). Os docentes de pós-graduação: grupo de risco de doenças cardiovasculares. Acta Scientiarum. Education, 33(2), 219-226.

Volpato, G. L. (2013). Ciência: da filosofia à publicação (6. ed. rev. ampl.). São Paulo: Cultura Acadêmica. 